\title{
A lógica financeira e o espaço do transporte aéreo comercial brasileiro
}

\author{
Financial logics and the brazilian aviation market
}

Martin Mundo Neto'

\begin{abstract}
Resumo: Este estudo focou a dinâmica das forças em um espaço particular: o espaço do transporte aéreo comercial brasileiro. Utilizando-se dos conceitos propostos pela análise institucional das organizações e pela sociologia econômica, foram analisadas as estratégias das empresas que dominam este mercado - a TAM Linhas Aéreas e a GOL Linhas Aéreas - e algumas implicações para a estruturação atual. A partir das informações institucionais das empresas que dominam o mercado do transporte aéreo comercial brasileiro, de órgãos governamentais responsáveis pelo controle das atividades e daquelas veiculadas na imprensa de negócios, o estudo procurou indicar os atores responsáveis pela estruturação das empresas dominantes. As duas empresas operam tanto no espaço industrial original, transporte aéreo, como em mercado de capitais. O modelo de negócio da empresa GOL, notadamente a adesão aos investimentos de private equities, seria um dos fatores determinantes para a nova configuração deste espaço industrial. A TAM, no âmbito financeiro, adota estratégia semelhante à GOL. A recente crise aérea e a crise financeira impactaram fortemente as duas empresas, sobretudo no valor de suas ações.
\end{abstract}

Palavras-chave: Mercado do transporte aéreo. Sociologia econômica. Sociologia dos mercados. Teoria das organizações.

\begin{abstract}
This study focuses on the power dynamic of a particular space: Brazilian Airlines Companies. Applying the concepts of Organizational Theory and Economic Sociology, it was possible to analyze the strategies of TAM and GOL airlines, which are companies that dominate the aviation market. Gathering institutional information from those companies, from government entities which control those companies' activities, and also from the business media, this study focused on indicating the social actors responsible for structuring these dominant companies. Both companies operate in the aviation market, but they also operate in the stock market. GOL business model, particularly the use of private equities tools, can be considered a determinant factor for the new configuration of this industry. In terms of financial market, TAM adopts similar strategy to that adopted by GOL. The recent aviation crisis and the financial crisis of 2008 strongly affected both companies, particularly their stock market value..
\end{abstract}

Keywords: Aviation market. Economic sociology. Market sociology. Organizational theory.

\section{Introdução}

Na primeira década do século XXI, o mercado do transporte aéreo comercial brasileiro passou a ter uma configuração marcada pelo predomínio de duas empresas: a TAM Linhas Aéreas e a GOL Linhas Aéreas. Pretende-se, neste trabalho, contribuir para o entendimento desta configuração, indicando elementos das estratégias gerais adotadas pelas empresas dominantes, os atores que ocuparam posições-chave nas empresas e os desdobramentos considerados relevantes para a estruturação atual deste mercado, bem como indicar, em particular, os reflexos de tal configuração nas empresas concorrentes.

As mudanças na aviação teriam suas origens em mudanças de ordem mais geral. A partir de 1960, o Estado na América Latina sofreu influências diretas das transformações ocorridas no Estado norte-americano. A configuração de um Estado de Bem-Estar Social ("pesado"), influenciado pela tradição Keynesiana, muda para uma configuração neoliberal, amparado na ideia de Estado Mínimo ("leve"), sobretudo no que diz respeito à atuação nos mercados. Nesse processo, tanto as profissões como o conhecimento técnico, fundamentalmente em economia e direito, são exportados/importados do Norte para o Sul (DEZALAY; GARTH, 2000). O processo de desregulamentação dos mercados e redefinição do papel do Estado que teve início nos anos de 1970, nos Estados Unidos, se difundiu entre

\footnotetext{
${ }^{1}$ Professor pleno I da FATEC-TQ, Av. Dr. Flávio Henrique Lemos, 585, Portal Itamaracá, CEP 15900-000, Taquaritinga - SP,

E-mail: martin@dep.ufscar.br
} 
diferentes países. No Brasil, este processo ocorreu mais intensamente na década de 1990, apogeu das privatizações.

No mercado de transporte aéreo internacional, historicamente, predominaram as empresas estatais (PALHARES, 2002). O processo de desregulamentação do setor acarretou a privatização de várias empresas, justificada pela busca de maior eficiência e melhores serviços aos consumidores. No Brasil, essa tendência pode ser ilustrada pela trajetória da Viação Aérea São Paulo (VASP). A VASP foi criada pela iniciativa privada em 1933 e adquirida pelo Estado de São Paulo em 1935. Em 1990, ela foi privatizada, passando a integrar os negócios do grupo Canhedo (de propriedade do empresário Wagner Canhedo). Atualmente, a empresa encontra-se em recuperação judicial e o grupo Canhedo foi afastado da direção da empresa por determinação da justiça.

De acordo com Grün (2004), a economia financeira predominante defende que as riquezas da sociedade são mais produtivas quando estão sob propriedade de indivíduos, em comparação à situação na qual o Estado ou as empresas são os proprietários, uma vez que os primeiros seriam mais interessados em maximizar o lucro de seus investimentos. Nas grandes empresas, os interesses dos gerentes estariam em conflito com os interesses dos acionistas. E, no Estado, analogamente, os burocratas estariam preocupados em defender seus interesses em vez de maximizar a aplicação dos recursos públicos de forma a ampliar os benefícios para a sociedade.

O mercado de transporte aéreo estaria entre aqueles sob forte interferência do Estado. Historicamente, ele figura entre os mercados com maior regulamentação, seja por questões de segurança, seja por envolver o território de vários países, quando se trata do transporte aéreo internacional. A Internacional Civil Aviantion Organization (ICAO) é a organização, vinculada à Organização das Nações Unidas (ONU), responsável pela regulamentação do transporte aéreo internacional e que fornece a referência para a regulamentação específica de cada país.

Monteiro (2009) faz uma síntese sobre a relação do Estado e a indústria do transporte aéreo comercial brasileiro. Segundo o autor, até 1990, o transporte aéreo esteve sob forte regulação governamental. Durante a década de 1990, particularmente no governo de Fernando Henrique Cardoso, ocorreu um processo de desregulamentação deste mercado. As discussões sobre a privatização da Empresa Brasileira de Infraestrutura Aeroportuária (INFRAERO), estatal que administra a infraestrutura aeroportuária, voltaram para a pauta das estratégias para o desenvolvimento do setor. A construção das bases institucionais da Agência Nacional de Aviação Civil (ANAC) teria sido iniciada neste período e seguiria as orientações da "economia de mercado". Na primeira década do século XXI, teria ocorrido um crescimento da oferta em descompasso com a infraestrutura instalada. As mudanças institucionais em torno da criação da ANAC e a redefinição das atribuições dos demais órgãos governamentais correlatos teriam gerado uma falta de articulação e deficiências na gestão entre as atividades que compõem o sistema aéreo brasileiro, culminando na crise aérea e, posteriormente, no "apagão aéreo" (MONTEIRO, 2009). Para Lovadine (2009), a concentração deste mercado em torno das duas empresas (TAM e GOL), não implicou em falta de concorrência entre as empresas e prejuízo para os clientes.

A hipótese central deste artigo é que a lógica financeira estaria predominando entre as principais empresas do mercado de transporte aéreo comercial brasileiro, seguindo uma tendência do capitalismo contemporâneo. Se as empresas dominantes adotam estratégias distintas nas operações produtivas, notadamente em termos de preços, o mesmo não ocorre no espaço financeiro.

Utilizando-se dos conceitos propostos pela análise institucional das organizações e pela sociologia econômica, e a partir das informações institucionais das empresas que dominam o mercado do transporte aéreo comercial brasileiro, de órgãos governamentais responsáveis pelo controle das atividades e daquelas veiculadas na imprensa de negócios, o objetivo foi indicar os atores responsáveis pela estruturação das empresas dominantes e identificar fatores que contribuíram para a mudança na concepção de controle (FLIGSTEIN, 1990; 2001) ou na estrutura cognitiva (DIMAGGIO, 2003) de seus controladores. Procurou-se também indicar alguns desdobramentos no campo organizacional, em especial, nas estratégias das empresas desafiadoras.

\section{Aspectos metodológicos}

Para estudos em ciências sociais, Bourdieu (1989) indica uma sociologia reflexiva, segundo a qual o importante é o processo de definição e construção do objeto de pesquisa:

A noção de campo é, em certo sentido, uma estenografia conceptual de um modo de construção do objecto que vai comandar - ou orientar - todas as opções práticas da pesquisa. Ela funciona como um sinal que lembra o que há que fazer, a saber, verificar que o objecto em questão não está isolado de um conjunto de relações de que retira o essencial das suas propriedades (BOURDIEU, 1989, p. 27)

Para compreender a constituição e a consolidação de uma determinada empresa em determinado campo, Bourdieu (2005) sugere que sejam analisadas tanto a empresa em relação ao campo que a engloba como a própria empresa enquanto um campo relativamente 
autônomo. Seguindo as orientações do autor, neste trabalho, primeiro foi realizada uma síntese da trajetória histórica das duas empresas que dominam este mercado, indicando as ações estratégicas e o conjunto dos seus principais dirigentes - quadro de executivos.

O recorte temporal foi na primeira década do século XXI. Neste período, teriam ocorrido tanto a reestruturação da empresa TAM como a constituição e a consolidação da empresa GOL. Para confirmação do suposto predomínio da lógica financeira no campo do transporte aéreo brasileiro, foi analisada, no âmbito mais geral, a ocorrência de um grupo de atores particulares, investidores institucionais ligados à indústria de capital de risco (private equities $\mathrm{e}$ venture capital), que, segundo Folkman et al. (2006), atuariam como "intermediários do capitalismo financeiro contemporâneo". Procurou-se identificar se antes que as empresas ingressassem no mercado de capitais, teria ocorrido aporte de investidores institucionais, gestores de private equities, inclusive da BNDESPar (BNDES Participações - subsidiária do Banco Nacional de Desenvolvimento Econômico e Social, que atua na indústria de capital de risco) e de fundos de pensão.

No âmbito mais específico, após a abertura de capital das empresas, a atenção concentrou-se na Governança Corporativa por elas apresentada. Foi dada atenção especial para a composição do Conselho de Administração, para os respectivos presidentes executivos (Chief Executive Officer - CEO) e os vice-presidentes financeiros (Chief Finance Officer - CFO). Foram considerados os capitais relacionados ao quadro executivo das empresas, particularmente o capital escolar e o científico, caracterizado pela formação acadêmica e as escolas de formação dos profissionais; o capital organizacional, identificado pela trajetória profissional individual dos executivos; o capital político, relacionado à trajetória política e às ligações políticas e partidárias que esses indivíduos mantêm com atores da esfera externa à empresa; o capital simbólico, caracterizado pela legitimidade das suas ações junto a interlocutores internos à empresa e com os de fora dela. Eles seriam importante fonte de forças que sustentam as estratégias empresariais.

Também foram analisadas estratégias das empresas desafiadoras, procurando identificar relações com as estratégias adotadas pelas empresas que dominam o mercado. Os dados foram reunidos a partir das informações oficiais divulgadas pelas empresas estudadas e pelas organizações governamentais responsáveis pela regulamentação tanto do transporte aéreo como dos mercados financeiros brasileiro e norte-americano. A imprensa de negócios foi outra importante fonte de dados, uma vez que possibilitou encontrar a fala dos executivos das empresas estudadas. Nos discursos destes executivos, estariam presentes as justificativas para algumas das estratégias adotadas. Esta alternativa de coleta de dados foi adotada uma vez que a desejada, ou seja, a realização de entrevistas junto aos executivos citados no artigo, tinha restrições de tempo e de custos. Estudos correlatos complementaram o conjunto de dados apresentado.

\section{Referencial teórico}

Bourdieu (2005) propõe uma teoria econômica como ciência histórica, segundo a qual o mercado é entendido como uma construção social, na qual o Estado tem participação decisiva:

Os agentes criam o espaço, isto é, o campo econômico, que só existe pelos agentes que se encontram nele e que deformam o espaço na sua vizinhança, conferindo-lhe certa estrutura. Dito de outro modo, é na relação entre as diferentes "fontes de campo", isto é, entre as diferentes empresas de produção, que se engendram o campo e as relações de força que o caracterizam (BOURDIEU, 2005, p. 23).

Para Bourdieu (2005), em estudos sobre mercados, deve-se considerar a dinâmica dos principais agentes e das suas organizações de representação de interesses. Os capitais destes agentes influenciam a resultante das forças neste espaço e na posição relativa de cada um no espaço. O campo econômico é formado por subcampos, relativo ao conjunto das indústrias em determinada economia. Um determinado agente econômico possui uma força em um subcampo que é função do volume e da estrutura do capital que ele detém. O capital de determinada empresa apresenta-se simultaneamente em diferentes formas: financeiro, cultural, tecnológico, jurídico, organizacional, comercial e simbólico. Segundo o autor, a estrutura do campo e a distribuição dos capitais entre os agentes determinam o processo de reprodução do próprio campo.

As mudanças no campo estariam relacionadas ao conjunto de capitais mais relevantes, notadamente $o$ capital tecnológico. Os novos ingressantes em um campo estabilizado, geralmente, adotam a estratégia da fusão ou da aquisição de grupos que já operam no campo. Trata-se de atores que ocupam posição dominante em outro subcampo econômico, ou seja, são originais de outros campos, procurando por novas oportunidades. O campo econômico é um campo de lutas entre os diferentes atores (grupos empresariais) que dele participam. A disputa pelo poder nos diferentes espaços industriais tende à estabilização. Quando ela ocorre, constitui-se uma estrutura (de mercado) caracterizada pela polarização entre os que dominam o campo (dominantes/líderes) e os que ocupam uma posição secundária, na maioria das vezes inspirados nas estratégias dos primeiros (dominados/desafiadores). Os dominantes atuam no sentido de preservar ou melhorar sua posição 
no campo. No estudo de um determinado campo, interessam tanto as relações que se desenvolvem no seu interior como aquelas do campo com seu exterior.

Mas, entre todas as trocas com o exterior do campo, as mais importantes são as que se estabelecem com o Estado. A competição entre as empresas assume freqüentemente a forma de uma competição para o poder sobre o poder do Estado, - notadamente, sobre o poder de regulamentação e sobre os diretos de propriedade (Cf.J. Campbell, L. Lindberg. Property rights and the organization of economic action by the State. American Sociological Review, 55, 1990, p. 634-647.) - e para as vantagens asseguradas pelas diferentes intervenções do Estado, tarifas preferenciais, patentes, regulamentos, créditos para pesquisa-desenvolvimento, compras públicas de equipamentos, ajudas para a criação de empregos, inovação, modernização, exportação, habitação, etc. (BOURDIEU, 2005, p. 39-40).

O poder sobre o poder do Estado seria disputado pelos representantes de diversos campos organizacionais. Daí, por exemplo, num determinado campo industrial, os atores (grupos empresariais) competirem e cooperarem entre si. A cooperação entre os atores em um determinado campo, geralmente, pode ser percebida nas ações cujo objetivo é a defesa dos interesses dos participantes de um campo específico junto ao Estado.

Folkman et al. (2006) chamam atenção para um tipo de ator que estaria ocupando posição de destaque no capitalismo contemporâneo: os "intermediários". Trata-se de um grupo pouco homogêneo e sobre o qual há pouca informação disponível. Mas, entre eles, destacam-se os bancos de investimento, os escritórios de Direito Corporativo e os representantes da indústria de capital de risco - gestores de venture capital e private equity. Estes grupos especializados estariam ocupando posições chaves nas reestruturações corporativas e seriam também responsáveis pela difusão do capitalismo financeiro.

\section{Mercados como}

\section{campos organizacionais}

Fligstein (1990; 2001) apresenta uma abordagem cultural para o estudo dos mercados, inspirado na noção de campo de Bourdieu. Para Fligstein (1990; 2001), os mercados passam por pelo menos três fases: formação, estabilização e transformação. Nas grandes corporações norte-americanas, desde 1880, os dirigentes têm interpretado os ambientes, internos e externos, e procurado desenvolver ambientes favoráveis ao desenvolvimento e à estabilização dos diversos mercados. Para serem criados e se desenvolverem, os mercados dependeriam da existência de determinadas instituições.

O ingresso dos países no capitalismo leva seus Estados a desenvolverem regras sobre os direitos de propriedade, estrutura de governança, regras das transações econômicas e concepções de controle no sentido de estabilizar os mercados (FLIGSTEIN, 2001, p. 36).

Em um determinado mercado, grupos empresariais Responsáveis (Incumbents) atuam no sentido de consolidar sua posição em relação aos demais Responsáveis e aos Desafiadores (Challengers), levando a uma situação de estabilidade dos mercados. O objetivo central dos gestores seria controlar o ambiente no qual a organização esta inserida. Uma solução bem sucedida em um determinado espaço industrial torna-se uma referência, em termos organizacionais, para as demais empresas do campo organizacional. Para que os campos organizacionais se constituam, é necessário que os atores se reconheçam reciprocamente e compartilhem concepções de ações legítimas. Os mercados estáveis estariam estruturados como campos organizacionais. Os gestores e proprietários buscam, primeiramente, garantir a sobrevivência e o crescimento das grandes corporações e não maximizar os lucros, como pressupõe a ortodoxia econômica dominante. A ação dos executivos à frente das grandes corporações estaria relacionada à visão de mundo destes atores ou da concepção de controle predominante no seio da firma.

\section{Concepção de controle e governança corporativa}

Para Hirsh e De Souce (2006), a reestruturação organizacional seria uma ferramenta de gestão, tanto pelo papel retórico como pelas implicações para a organização do trabalho corporativo. Historicamente, ela estaria sendo utilizada para alterar as definições societárias e do trabalho assalariado. A reestruturação organizacional estaria presente tanto na esfera privada, como nas propostas e discursos políticos.

Segundo Fligstein (1990):

Concepção de controle refere-se a uma visão totalizante do mundo dos gerentes ou empreendedores que os levam a filtrar os problemas do mundo num certo sentido [...] Uma estratégia organizacional refere-se aos objetivos atuais da organização e as políticas adotadas para alcançar aqueles objetivos. A concepção de controle refere-se a por que gerentes enxergam aquelas estratégias como apropriadas para o que a empresa deve fazer (FLIGSTEIN, 1990, p. 10-1).

Desde o início do capitalismo industrial, cinco concepções de controle predominaram, em momentos 
distintos, nas grandes corporações norte-americanas. No início, a concepção de controle direto teria levado à elaboração de estratégias de ataque aos principais concorrentes. Caso esta tática falhasse ou fosse difícil de ser aplicada, os empreendedores uniam-se. A competição por preços e a constituição de cartéis eram as estratégias mais utilizadas neste período. $\mathrm{Na}$ segunda concepção de controle - controle baseado na manufatura -, o objetivo

“[...] é produzir um produto sem a interferência dos competidores controlando as entradas e as saídas por meio de integração vertical e horizontal de produção" (FLIGSTEIN, 1990, p. 14).

Como estratégias, destacam-se a integração vertical das atividades produtivas, as operações de aquisições e fusões, visando ampliar a participação de mercado e os oligopólios baseados em determinados produtos. A terceira concepção de controle, de vendas e marketing, leva seus adeptos a focar o mercado, ou a manutenção e a ampliação das fatias de mercado. As principais estratégias seriam: a diferenciação dos competidores em termos de qualidade do produto e preço; mais propaganda para aumentar a participação de mercado; novos produtos para estimular o crescimento e expandir os mercados para produtos existentes, particularmente os mercados internacionais (FLIGSTEIN, 1990).

Para o autor, a concepção de controle financeira

[...] enfatiza controle por meio do uso de ferramentas que medem o desempenho de acordo com taxas de retorno [...] As estratégias chaves são: diversificação através de fusões e desinvestimentos (em oposição à expansão interna); táticas financeiras para aumentar o preço das ações, dívidas e habilidade para absorver outras empresas; e o uso de controles financeiros para tomar decisões sobre a alocação interna de capital (FLIGSTEIN, 1990, p. 15).

Fligstein (2001) apresenta a concepção de controle dominante no capitalismo contemporâneo como uma variante da concepção financeira. Segundo o autor, durante a década de 1980, o ambiente econômico norte-americano (as altas taxas de inflação, o baixo crescimento econômico e o baixo desempenho financeiro das grandes corporações, particularmente em termos do valor das ações no mercado de capitais) criou as condições favoráveis a uma nova onda de fusões. A intensificação do mercado de fusões e aquisições, e a ampliação da participação de investidores institucionais no mercado de capitais, particularmente os fundos de pensão, bancos de investimentos e companhias de seguro, foram fatores que contribuíram para o surgimento da concepção de controle que valoriza o acionista (shareholder value conception of control). A principal diferença entre a nova concepção de controle e a anterior seria o fato de que, na anterior, os administradores não estariam gerenciando os ativos de modo a maximizar o que veio a ser denominado de "valor do acionista" (FLIGSTEIN, 2001). As estratégias resultantes da nova concepção de controle seriam de natureza financeira, mas procuram privilegiar os acionistas e não os gerentes que, na versão anterior, além de muito numerosos, recebiam salários elevados. Uma importante construção da concepção de controle baseada no valor do acionista é a Governança Corporativa (GC).

De acordo com Boltanski e Chiapello (2009, p. 109),

[...] pode-se considerar a história da gestão empresarial como a história da sofisticação permanente dos meios de dominar aquilo que ocorre na empresa e em seu ambiente. Se, em Taylor e Fayol, considerados os fundadores da gestão empresarial como disciplina, os seres humanos são o ponto principal de aplicação dos controles (o par homem-máquina em Taylor, organização geral em Fayol), mais tarde, a vontade de domínio, com certas subdisciplinas da gestão empresarial, se estenderá para além do controle das máquinas e do pessoal. Com a estratégia empresarial, desenvolveu-se o domínio dos mercados e da concorrência; com o marketing, o domínio do circuito de distribuição, dos clientes e de seus comportamentos aquisitivos; com a gestão de compras, o controle dos fornecedores; com as relações públicas, o da imprensa e dos poderes políticos. Do mesmo modo, no pessoal, cada categoria passou a ser alvo de dispositivos específicos: o taylorismo foi inventado para controlar os operários, e a administração por objetivos, para enquadrar os executivos; hoje em dia, os dispositivos da "governança corporativa" (corporate governance) destinam-se ao controle dos mais altos dirigentes das grandes empresas.

De acordo com Grün (2003), na esfera do simbólico, o ideário da governança corporativa reforçaria os valores individuais, representados pela figura do acionista minoritário. Em contrapartida, a valorização dos direitos individuais reduziria a relevância dos direitos coletivos. As transformações no capitalismo contemporâneo estariam relacionadas com " [...] a associação do conceito de cidadão ao de acionista minoritário, vinculando a nova representação da empresa à nova representação do Estado" (GRÜN, 2003, p. 146).

A versão mais recente da lógica financeira tem suas bases nos pressupostos da teoria econômica neoclássica, mais especificamente na teoria dos contratos ou teoria da agência (FAMA, 1980). Para o autor, as empresas são "feixes" de contratos: de um lado, o principal (acionistas); e do outro, 
o agente (colaboradores, gerentes, executivos). $\mathrm{O}$ problema da teoria da agência é contornar a assimetria de informação entre os agentes participantes dos contratos. A GC seria uma prescrição desta corrente teórica para a gestão dos grandes grupos econômicos contemporâneos.

A GC é uma criação do mercado de capitais norte-americano. Originalmente, ela prescreve a transparência contábil, o respeito ao acionista minoritário e a possibilidade de tomada do controle acionário da empresa por meio de compra de suas ações no mercado de capitais (GRÜN, 2005). A GC seria uma das mais importantes construções da concepção de controle baseada no valor do acionista. Os conselhos de administração e as diretorias executivas, em especial os presidentes executivos (Chief Executive Officer - CEO) e os diretores financeiros (Chief Finance Officer-CFO), estariam entre os principais indicadores da boa GC. As "boas práticas" de GC estariam fortemente ligadas à qualidade do grupo de executivos presentes em cada empresa. Por sua vez, as decisões tomadas pelos executivos estariam fundamentadas em indicadores de desempenho de natureza financeira.

Segundo o Instituto Brasileiro de Governança Corporativa (IBGC), GC é um sistema de gestão empresarial para as empresas estruturadas como sociedade de ações. As boas práticas de GC têm como objetivo valorizar a empresa e contribuir para a sua perenidade. A preocupação da GC seria assegurar que o comportamento dos executivos esteja sempre alinhado com o interesse dos acionistas. As principais ferramentas que asseguram o controle da propriedade sobre a gestão seriam o conselho de administração, a auditoria independente e o conselho fiscal (INSTITUTO..., 2009).

No início desta década, em 2001, foi instituído o Novo Mercado da Bolsa de Valores de São Paulo (BOVESPA), fundamentado em um sistema de classificação para os diferentes níveis de GC adotada pelas empresas. $\mathrm{O}$ fortalecimento do mercado de capitais brasileiro seria um dos desdobramentos do processo de transformação que se iniciou na década de 1990, primeiro com as privatizações e, posteriormente, na intensificação das operações de fusão e aquisições entre empresas, com participação de investidores institucionais nacionais e internacionais (Donadone; Sznelwar, 2004). Segundo Zilbovicius e Dias (2005), as decisões na esfera produtiva estariam subordinadas às da esfera financeira, um processo descrito pelos autores como "financeirização da produção".

O modelo de negócio que passou a prevalecer entre os grandes grupos econômicos é o de empresa de acionistas, cuja difusão teria sido potencializada pela participação de investidores institucionais, sejam os fundos de pensão, conforme demonstrado por JARDIM (2007), sejam os gestores de fundos de private equities (GRÜN, 2009), ou ainda o Estado, por meio da BNDESPar (MUNDO NETO, 2008). $\mathrm{Se}$, nos últimos anos, o capitalismo brasileiro tem se transformado em capitalismo acionário (JARDIM, 2007), as mudanças nas empresas TAM e GOL ilustrariam como esta nova configuração mais geral se reflete no arranjo interno das empresas. Ambas adotaram estratégias corporativas semelhantes, estruturando-se como empresa de capital aberto, participando tanto da bolsa de Nova Iorque (New York Stock Exchange - NYSE) como da BM\&F BOVESPA (companhia resultante da fusão, em 2008, entre a Bolsa de Valores de São Paulo - BOVESPA e a Bolsa de Valores, Mercadorias e Futuros - BM\&F).

\section{A empresa TAM}

A TAM, criada em 1960, permanece regional até o final da década de 1980. Com o início do processo de desregulamentação e com a privatização da VASP, ela passa a despontar como uma empresa que operará em escala nacional, evoluindo gradativamente durante a década seguinte. Durante esse período, a empresa teve de equacionar os desafios do crescimento com a necessidade de se adequar às novas tendências desse espaço. Após a crise da VARIG, ela assumiu a liderança neste mercado. A TAM desenvolveu uma estratégia calcada na busca da qualidade total dos serviços ("Tapete vermelho" aos passageiros). Essa estratégia reflete o predomínio da lógica industrial durante a maior parte da história da empresa. A apresentação institucional da empresa deixa evidente $\mathrm{o}$ papel do comandante Rolim - primeiro, como piloto; depois, como principal acionista da empresa - para a consolidação da cultura da organização em torno dos valores relacionados à qualidade e à preocupação com os clientes (passageiros).
A Companhia acredita ter uma forte cultura corporativa, legado de seu fundador, Comandante Rolim Adolfo Amaro, que permeia todos os níveis da Companhia e continua a nortear as ações da Administração em seu dia-a-dia. Essa cultura é evidenciada por toda sua linha de frente e integra os treinamentos oferecidos aos novos colaboradores de forma que toda a Companhia atue em consonância com as melhores práticas e seu diferencial de serviços (TAM, 2007).

A diferença fundamental está na ampliação dos tipos de cliente da empresa: "cliente passageiro" e "cliente investidor". A ênfase desloca-se para a gestão financeira e os seus desdobramentos subordinam as atividades "originais", uma vez que a

“[...] prioridade estratégica da TAM é consolidar e ampliar a liderança no mercado doméstico de passageiros, obtendo alta rentabilidade." (TAM, 2007). As suas estratégias são: “a) 
Dar continuidade ao seu atendimento de alta qualidade [...]; b) Aumentar a receita com rentabilidade, servindo um maior número de passageiros a preços competitivos [...]; c) Reduzir os seus custos operacionais, otimizando a utilização de sua frota e os seus processos [...]" (TAM, 2007).

Essas diretrizes explicitam um processo de transição no foco estratégico da empresa, antes predominantemente calcado na qualidade total e depois centrado na reengenharia das operações produtivas. $\mathrm{O}$ modelo de gestão prescrito pelo mercado financeiro é adotado como referência.

As ações preferenciais da TAM (“TAMM4”) estão listadas no Nível 2 de governança corporativa da Bovespa. A decisão de aderir ao Nível 2 de governança corporativa da Bovespa traz diversos benefícios aos investidores, pois permite (i) maior acuidade na precificação das ações; (ii) melhora no processo de acompanhamento e fiscalização dos negócios da companhia; (iii) maior segurança quanto aos seus direitos societários; e (iv) redução do risco associado ao investimento (TAM, 2007).

Em 2005, a empresa TAM, praticamente um ano depois da empresa GOL, ingressa no novo mercado da BOVESPA (Bolsa de Valores de São Paulo) e, posteriormente, na NYSE. A comunicação efetuada pela Equipe de Relações com Investidores - TAM Linhas Aéreas, em 1/3/2007, por meio de correio eletrônico, atendendo a solicitação do autor, esclarece a questão:

"O nosso IPO (Initial Public Offer) ocorreu em 14/06/2005, antes disso, nós possuíamos um pequeno número de ações e sem liquidez na Bovespa. Fizemos o Follow on em 10/03/2006 com ações na Bovespa e NYSE"

A TAM, assim como a GOL, contou com a participação de gestores de fundos de private equity na sua reestruturação. Os investimentos dos fundos foram realizados na segunda metade da década de 1990, pelo banco Garantia (banco de investimento), mas com um resultado bem menos expressivo que o obtido pelo gestor do fundo que investiu na concorrente (ADACHI, 2005). Após abrir o capital, a TAM amplia sua participação no mercado e suas ações valorizam-se. Mas até o início da crise aérea, ela tinha apresentado um desempenho inferior ao da empresa GOL, tanto nas atividades operacionais como nos mercados de capitais das quais participam. No âmbito financeiro, a semelhança de estratégias entre a TAM e a GOL pode ser confirmada por meio da comparação dos indicadores ou "selos" de mercado adquiridos por ambas. As duas estão classificadas no nível N2 do Novo Mercado da BM\&F BOVESPA. Antes de ingressarem no IBOVESPA, as duas empresas ingressaram nos indicadores de GC, demonstrando a importância destes índices secundários para as novatas no mercado de capitais, notadamente em termos de ampliação da legitimidade e da confiabilidade junto aos investidores.

Tanto a TAM como a GOL, logo após estrearem na BOVESPA, ingressaram no Índice de Sustentabilidade Empresarial (ISE) da BOVESPA, instituído em dezembro de 2005. Esta estratégia ilustra a preocupação dessas empresas com a forma como se apresentam perante a sociedade. Grosso modo, o índice sinaliza para a sociedade e, em particular, para os investidores, que as empresas nele classificadas desenvolvem ações de responsabilidade social e de gestão ambiental, adotam "boas práticas de governança corporativa", além de serem eficientemente econômicas. Este indicador teria a função de sinalizar para a sociedade quais atores operam no mercado financeiro, mas que não colocam o lucro como o único objetivo a ser atingido. As operações econômicas de seus detentores teriam sua legitimidade ampliada na esfera social.

Além do ISE, desde que ingressaram no mercado financeiro, as duas empresas procuraram obter o maior número de certificados possíveis no espaço: ITAG (índice que mede o respeito ao acionista minoritário); IGC (índice organizado pelo IBGC para atestar a existência de boas práticas de GC); IBOVESPA (principal indicador financeiro da BM\&FBOVESPA); $\mathrm{IBrX}$ (indicador de desempenho de uma carteira hipotética das cem principais ações negociadas na BM\&FBOVESPA); IBrX50 (idem a IBrX para as cinquenta principais ações da bolsa); IVBX2 (indicador financeiro criado pela Bolsa e pelo jornal Valor Econômico). Grande parte desses índices são indicadores de governança corporativa. Ao valorizar a obtenção desses índices, as empresas demonstram a preocupação em apresentarem-se conforme o padrão predominante no espaço financeiro. $\mathrm{O}$ índice mais cobiçado na BOVESPA, o IBOVESPA, só foi adquirido pelas empresas TAM e GOL a partir do segundo semestre de 2006, depois dos demais índices que atestam GC. Esse fato indica, pelo menos parcialmente, que as "novatas" do espaço financeiro têm primeiro que ganhar credibilidade junto aos investidores. Elas perseguem os índices "secundários" para então figurarem entre aquelas cujos papéis são amplamente procurados.

A partir de 2007, tanto a TAM como a GOL, foram excluídas do ISE. Apenas a empresa GOL respondeu ao questionamento sobre quais as razões que levaram a empresa a ser excluída do ISE. Um responsável pelo relacionamento com investidores sugeriu que a resposta fosse solicitada junto à BOVESPA, uma vez que ela é a responsável pelo índice. A BOVESPA, por sua vez, respondeu ter uma política de não revelar os motivos em consideração às empresas que participam 
do processo de seleção para composição do índice. Portanto, não há justificativa oficial para a exclusão das empresas que estiveram no índice.

Na TAM, durante a crise aérea, as declarações da presidente do conselho de administração indicam a preocupação com o resgate da imagem e anunciam as mudanças internas. Sucedendo sua mãe na presidência do conselho de administração da empresa, em abril de 2007, logo após assumir o cargo, Maria Cláudia Amaro Demenato, filha mais velha do comandante Rolim, declarou que a "[...] TAM estava com crise de identidade e foi fazer terapia [...], o crescimento exagerado faz com que uma empresa perca os valores. Vamos reforçar nossa origem e identidade" (CAMPASSI; ADACHI, 2007).

Se a empresa não estava bem, sua governança deveria ser revista.

\section{Mudanças na governança corporativa da empresa TAM}

Uma das medidas tomadas pela alta direção da empresa TAM foi substituir seu diretor de planejamento. Gelson Pizzirani foi desligado da diretoria no dia 1/3/2007, assumindo a função Paulo Cezar Castello Branco. A justificativa apresentada pela empresa para essa medida foi que a decisão estava vinculada ao processo de reestruturação em curso desde meados de 2006. Porém, é difícil desassociar este fato dos problemas de atrasos de voos ocorridos no final de 2006 (Campassi, 2007a). Segundo especialistas do setor aéreo, os problemas ocorridos estariam relacionados à tentativa da empresa TAM em atingir a taxa de utilização alcançada pela empresa GOL para conseguir reduções de custos que possibilitassem um desempenho semelhante à principal concorrente.

“[...] A TAM é uma empresa de muitos anos. Não muda da noite para o dia, de uma companhia aérea tradicional para uma de baixo custo. Não dá para ser a Gol, diz Daniela Bretthauer, analista do Santander Investment. (ADACHI et al., 2006).

De acordo com as informações oficiais divulgadas pelas empresas, enquanto o tempo médio de operação das aeronaves da GOL, em 2006, foi de 14,2 horas/ dia, a média da TAM não havia ultrapassado a marca de 12 horas/dia.

O acidente do voo 3054 da empresa TAM, em julho de 2007, acentuou ainda mais o cenário de "caos" aéreo e trouxe à tona a hipótese de que uma das possíveis causas do acidente derivaria da busca frenética da empresa TAM pela melhoria do seu desempenho operacional. A política de manutenção adotada pela empresa, tanto a manutenção de longa duração ("pesada") como aquela realizada entre pousos e decolagens, passou a ser objeto de investigação policial.

De forma semelhante às medidas tomadas para solucionar os problemas de planejamento da empresa, a alta direção toma uma decisão emblemática: substituir o diretor de operações. A empresa TAM foi buscar na sua maior concorrente o comandante David Barioni Neto, que desde a criação da empresa GOL ocupava a posição de vice-presidente técnico. Barioni chega com a tarefa de reestruturar a área operacional e resgatar a imagem da empresa enquanto referência em qualidade no transporte aéreo (CAMPASSI, 2007a). Alguns meses depois, Barioni torna-se o novo presidente da empresa TAM, sucedendo Marcos Bologna, executivo do mercado que, a partir de 2004, operou a reestruturação da empresa, preparando-a para a abertura de capital tanto na BOVESPA como na NYSE. Contudo, Marcos Bologna fica pouco tempo afastado da TAM. Retorna como conselheiro da TAM Empreendimentos e Participações (TEP), empresa da família controladora da TAM Linhas Aéreas, e posteriormente assume a presidência da TAM Aviação Executiva, considerada o embrião dos negócios do grupo. Cabe ressaltar que a TEP é a acionista majoritária da TAM Linhas Aéreas e que o fundo de investimento norte-americano Blackrock, mesmo com participação minoritária, reforça a lógica financeira no grupo.

Entre as empresas que apresentam sua GC, é comum a apresentação de minicurrículos dos membros do Conselho de Administração e da Diretoria Executiva, na medida em que enfatizam a formação acadêmica do executivo e as respectivas instituições de ensino, bem como a sua trajetória profissional, a experiência internacional e as atividades desenvolvidas no âmbito do Estado. Nas informações disponibilizadas pela TAM sobre David Barioni Neto, tanto como novo diretor de operações e posteriormente presidente executivo (CEO), não constavam citações sobre sua passagem pela empresa GOL.

A crise financeira impactou particularmente as empresas aéreas, dado seu elevado grau de endividamento ou "alavancagem" financeira. A chegada de Barioni foi uma importante mudança no quadro de executivos da TAM, mas não a única. Barioni conduziu uma reestruturação focada na área operacional e, particularmente, na alta gerência da TAM. Por vir de "fora" e com a legitimidade de ter contribuído para a consolidação da principal concorrente, encaixou-se plenamente neste projeto. Conforme indicado por Boltanski e Chiapello (2009), David Barioni Neto, à frente da empresa TAM, ilustrou a orientação para projetos que, atualmente, os altos executivos dos grandes grupos econômicos são "convidados" a aderir. Em maio de 2009, a TAM, sob o comando de Barioni, dispensou 21 executivos. No final de julho deste mesmo ano, o banco de 
investimento BTG, liderado por André Esteves, foi contratado para dar consultoria financeira ao grupo. $\mathrm{Na}$ ocasião, foram indicados para o Conselho de Administração da TAM, tanto André Esteves como Marcos Bologna. Bologna retorna fortalecido e numa posição diferenciada. No início de outubro de 2009, Barioni deixa a presidência da TAM. Líbano Barroso, executivo trazido para a TAM por Bologna e que ocupava a posição de diretor financeiro (CFO), assume interinamente a presidência (CEO). No final de dezembro, Barroso, torna-se o presidente efetivo da TAM.

A troca de altos executivos na TAM demonstra a relevância que a GC passou a ter para as empresas que operam nos mercados de capitais. $\mathrm{Na}$ fase de preparação para abertura de capital, Bologna, primeiro ocupou a diretoria financeira (CFO), depois assumiu a presidência (CEO). Na crise aérea, a TAM, com desempenho operacional inferior à GOL, traz para a presidência um executivo da área de operações, com o objetivo de resgatar a credibilidade operacional. Passada a turbulência, retorna à presidência um executivo ligado à área financeira e que havia participado da sua preparação para abertura de capital.

\section{A empresa GOL}

As mudanças operadas na empresa TAM estão estreitamente relacionadas com o desenvolvimento da empresa GOL. O surgimento da empresa GOL impôs novos constrangimentos às empresas que já atuavam no espaço. Apesar de nascer como empresa familiar, sua configuração inicial está "geneticamente" dotada da lógica predominante no espaço das grandes empresas, pois sua transformação de empresa familiar para empresa de capital aberto teria sido cuidadosamente arquitetada. Tanto o modelo de gestão focado na minimização dos custos e na oferta de passagens a preços mais baixos como o seu rápido ingresso no mercado de capitais irão influenciar significativamente as demais empresas - particularmente a TAM e a VARIG -, além de se tornar referência para empresas menores e mais novas como a BRA Linhas Aéreas, a WEBJET Linhas Aéreas e, mais recentemente, a AZUL Linhas Aéreas.

A empresa GOL surge e procura desenvolver estruturas para atuar tanto no transporte aéreo como no mercado financeiro. A estratégia é se diferenciar adotando um modelo, que se mostra novo para as empresas brasileiras, mas com inúmeros representantes no mercado internacional: "low cost, low fare" (baixo custo, baixa tarifa). Longe de ser apenas uma oportunidade de negócio bem explorada, a trajetória da empresa GOL estaria estreitamente relacionada tanto com o volume como com a especificidade do capital da família proprietária na ocasião da sua formação: a família Constantino, proprietária do Grupo Áurea, um dos maiores grupos brasileiros na atividade de transporte rodoviário de passageiros, atuando tanto no transporte urbano como no intermunicipal e no interestadual.

Contudo, para atingir seu objetivo, a família Constantino teve de operar uma reconversão deste capital para que ele possibilitasse a criação e a configuração atual da empresa GOL. A nova empresa passa a adotar artefatos culturais ausentes até então nos negócios da família. O próprio caráter familiar tinha de ser erradicado. Para tanto, observa-se a preocupação em desvincular a imagem da empresa com os demais negócios da família controladora. No segundo para terceiro ano da empresa, um fato relevante ocorreu com a sua estrutura de capital. Em 2003, o grupo AIG Capital, subsidiária do American Internacional Group, que atua na indústria de capital de risco no Brasil, notadamente em operações de private equities, investiu um montante que representava 20\% do capital total da empresa. Mas, além do aporte financeiro, segundo a Associação Brasileira de Private Equity e Venture Capital (ABVCAP), o grupo AIG executou magistralmente a "receita" da indústria de capital de risco para as operações em private equity: primeiro, estruturar e preparar a abertura de capital da empresa; em seguida, trabalhar para a valorização do preço das ações e, então, vender a participação realizando altos lucros. Representantes do grupo AIG, em acordo com os membros da família Constantino que criaram a GOL (o pai e os três filhos), recrutaram um grupo de executivos para o conselho de administração, para as diretorias executivas e demais funções operacionais. Adotaram o modelo de empresa de acionistas e a governança corporativa. Entretanto, desde a constituição da empresa GOL, a presidência executiva (CEO) esteve com Constantino de Oliveira Júnior, o mais novo dos irmãos Constantino.

Corroborando as afirmações de Bourdieu (2005), o sucesso da empresa GOL pode ser entendido não como a vitória de uma pequena empresa no campo do transporte aéreo, mas sim como o resultado da investida, no campo do transporte aéreo, de um grande grupo, detentor de um determinado conjunto de capitais, vinculados fundamentalmente à sua trajetória no campo do transporte rodoviário, no qual ocupou posição entre as empresas líderes. A formação da empresa GOL mobilizou, inicialmente, um capital (volume e estrutura) que desde o início forçou uma reestruturação do campo, redefinindo tanto a oferta como a demanda de transporte aéreo.

Fligstein (2003) chama atenção para a importância que as instituições de mercado (os direitos de propriedade, as estruturas de governança, as concepções de controle e as normas de transação) têm na construção do projeto da empresa. No caso da empresa GOL, a mudança de natureza tipicamente familiar, passando por uma empresa S.A. de capital fechado para finalmente tornar-se uma S.A. de 
capital aberto, envolveu a modificação e a criação de instituições de mercado, e da própria cultura organizacional daqueles envolvidos nesse processo. É importante destacar a participação de atores chaves nesse processo, em particular dos representantes do fundo de private equity AIG.

Com o sucesso do lançamento das ações da GOL na BOVESPA, alguns de seus diretores foram beneficiados com a política de stock options (opções de compra de ações) antes de a empresa abrir seu capital: "Um restrito grupo de vice-presidentes da Gol recebeu lote de 937 mil opções, com preço de aquisição atualizado equivalente a $\mathrm{R} \$ 2,8$ milhões. Essas ações valem agora R $\$ 70$ milhões." (ADACHI; D'Ambrosio, 2006). Em maio de 2006, foi o momento em que as ações da empresa GOL alcançaram sua maior cotação ( $\mathrm{R} \$ 82,80$ em 8/5/2006) e a empresa foi considerada tanto um exemplo bem sucedido entre as novas participantes do mercado de capitais como também entre as operações da indústria de capital de risco no Brasil. De acordo com a ABVCAP, o caso da empresa GOL tornou-se exemplo de atuação dos gestores de private equities no país. Ao se retirar do negócio, o gestor do fundo obteve um retorno da ordem de 10 vezes o valor investido. "Outro gestor que não pode reclamar é a AIG Capital, que em duas vendas de ações da companhia aérea Gol, conseguiu R \$ 620 milhões." (Silva Júnior, 2006).

Um episódio envolvendo a família controladora da empresa GOL merece atenção, pois expõe como a lógica financeira se enraíza entre os representantes da família. O aprendizado obtido pela família Constantino com a abertura do capital da empresa GOL, assistido pelo grupo AIG e também por profissionais, como o conselheiro independente Antônio Kandir, levou a família Constantino a criar o grupo ASAS investimentos (Fundo de Investimentos em Participações Volluto), controlador da empresa GOL. Por meio do ASAS, a família Constantino passou a atuar nos moldes de um gestor de private equity. A primeira investida significativa foi realizada, no final de 2006, em parceria com o grupo AIG e com o grupo Governança \& Gestão (gestor de fundos de private equity controlado por Antônio Kandir conselheiro da empresa GOL) e pelo banco de investimento português Banco Espírito Santo: os quatro atores adquiriram a empresa PROVIDÊNCIA (do setor químico e de não tecidos), numa transação de quase um bilhão de reais, com a participação proporcional de $28 \%, 29 \%, 29 \%$ e $14 \%$, respectivamente. Menos de um ano depois, em 2007 a PROVIDÊNCIA ingressou na Bovespa. Até o momento atual, o desinvestimento não ocorreu e o controle continua com os investidores representados no Conselho de Administração (PROVIDÊNCIA, 2010).

A crise aérea, num primeiro momento, beneficiou enormemente as duas maiores empresas: TAM e GOL.
Mas, após o acidente aéreo de setembro de 2006, as duas empresas passaram a enfrentar situações adversas que, pelo menos aparentemente, têm causado grandes prejuízos, tanto de imagem quanto financeiro, para ambas. Desde a aquisição da empresa Varig, as ações da empresa GOL sofreram uma maior desvalorização do que as da TAM. Em setembro de 2007, o patriarca da família controladora da empresa GOL e então presidente do conselho de administração, Sr. Nenê Constantino, manifestou-se favorável ao fechamento do capital da empresa. Mesmo a empresa GOL sendo detentora de diversos índices que indicam a presença de "boas práticas de governança corporativa", existiria ainda um elevado grau de concentração de poder nas mãos da família controladora, o que contraria a prescrição dos teóricos da GC.

Em abril de 2009, as ações atingiram sua cotação histórica mínima, $\mathrm{R} \$ 6,58$, menos de $25 \%$ do valor da ação na ocasião de seu lançamento na BOVESPA. Este fato indica que mesmo o investimento na capacidade produtiva, ou seja, o aumento do tamanho das empresas, tanto da empresa TAM como da empresa GOL, e a tendência de crescimento da demanda por transporte aéreo dos últimos anos, não evitaram a desvalorizam de suas ações (Figura 1). Esta desvalorização acentuada ilustra o "descolamento" entre o valor patrimonial (ligado ao mundo produtivo) e o valor das ações da empresa (aspecto central para o mercado de capitais) no mundo financeiro. Diante do longo período de desvalorização de suas ações (desde o final de 2007) e para melhorar sua imagem em relação à GC "familiar", em abril de 2009, a presidência do Conselho de Administração passou a ser ocupada por Álvaro de Souza, um executivo "do mercado", conselheiro da empresa desde 2004. Um ano depois, em 1/4/2010, a cotação das ações era $\mathrm{R} \$ 22,79$, valorização de $246 \%$, enquanto, no mesmo período, o Ibovespa teve um crescimento de 74\% (de 40.925 para 71.136 pontos).

\section{Desdobramentos da estratégia dominante no campo organizacional}

O modelo de negócio adotado pela empresa GOL repercutiu no espaço do transporte aéreo, afetando as duas maiores empresas: a VARIG e a TAM. A primeira, que já enfrentava problemas financeiros, gradativamente perde participação de mercado e não consegue um desempenho operacional similar ao novo padrão estabelecido pela novata. A crise da empresa VARIG teve seu desfecho num longo e desgastante processo de leilão, acarretando prejuízos a um grande contingente de clientes, acionistas e funcionários, que só não foi maior graças à intervenção do Estado. Meses após o leilão da VARIG, a GOL anuncia a aquisição da empresa que estava sob o controle de um gestor de 


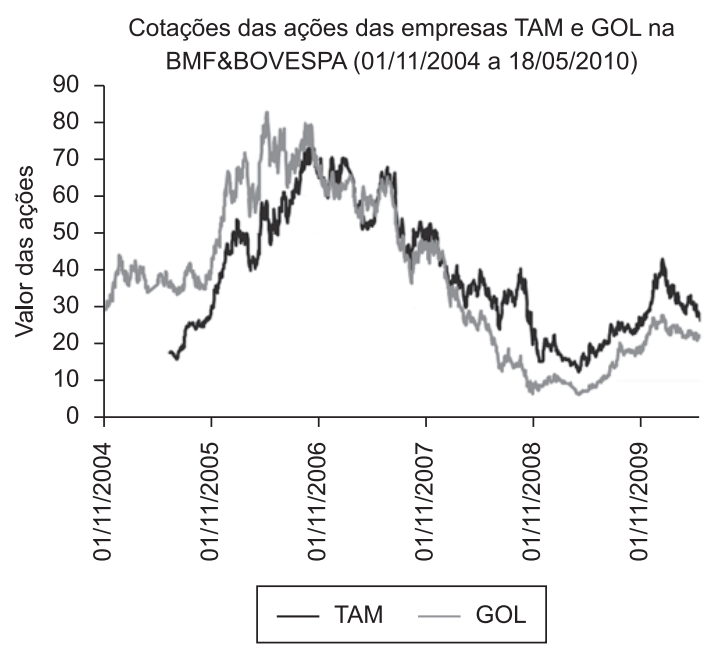

Figura 1. Cotações das ações das empresas TAM e GOL na BM\&F BOVESPA (1/11/2044 a 18/5/2010). Fonte: Elaborado pelo autor.

fundos de private equities que administrava recursos de investidores institucionais, sendo, fundamentalmente, fundos de pensão norte-americanos.

No final de 2006, investidores ligados à indústria de capital de risco, entre os quais o grupo Gávea investimentos (fundado e gerido pelo ex-presidente do Banco Central Armínio Fraga), adquiriram 20\% do capital da BRA Linhas Aéreas (RITTNER, 2006). A iniciativa demonstrou, mais uma vez, a forte presença dos gestores de fundos de private equities neste mercado específico. Porém, nesse caso, a iniciativa dos investidores foi frustrada, uma vez que o fundador da empresa se recusou a cumprir as orientações dos novos sócios. O caso se tornou um exemplo de negócio fracassado da indústria de capital de risco. Na ocasião, Armínio Fraga, atual presidente do conselho de administração da BM\&FBOVESPA, justificou-se lembrando que se tratava de uma oportunidade promissora, mas que teria também alertado para o alto risco e que o capital próprio (da Gávea investimentos) no negócio era ínfimo (VALOR ONLINE, 2007a). No fracasso, "minimizar os prejuízos" seria o ensinamento de Fraga para manter o prestígio no mundo das finanças.

Em março de 2008, David Neeleman, fundador da empresa aérea norte-americana JETBLUE, comunicou a constituição de uma nova empresa aérea brasileira: a AZUL Linhas Aéreas (VALOR ONLINE, 2008). Nessa nova iniciativa, também ocorre participação dos fundos de private equity (CAMPASSI, 2008). Novamente, o grupo Gávea participou da constituição e da elaboração da estratégia da nova empresa, persistindo na oportunidade de negócio na indústria de transporte aéreo, frustrada com a BRA. Com a redefinição da nova malha do setor aéreo brasileiro, as aeronaves da família EMB - 190 e 195, produzidos pela EMBRAER, foram escolhidas pela nova empresa, pois seriam mais apropriadas para rotas curtas do que as aeronaves das empresas TAM e GOL. Entre os investidores da AZUL, está a Cia. Bozano, terceira maior acionista da empresa EMBRAER. A AZUL segue o modelo da americana JETBLUE que, nos Estados Unidos, explora os voos regionais, opera preferencialmente em aeroportos secundários e utiliza as mesmas aeronaves produzidas pela EMBRAER.

Atualmente, na esfera legislativa, está em estudo uma proposta que amplia o teto para participação de investidores internacionais em empresas aéreas brasileiras, de $20 \%$ para até $49 \%$ do capital total. O empresário Guilherme Paulus, acionista controlador da WEBJET Linhas Aéreas, empresa que ocupa a terceira posição no ranking das empresas aéreas brasileiras, afirmou, recentemente, ter interesse em negociar a empresa com uma grande companhia europeia (KOMATSU, 2010).

\section{Considerações finais}

Para expandir sua capacidade produtiva e conquistar fatias de mercado, as empresas aéreas dependem de capacidade de investimento e de autorizações governamentais. O volume de capital exigido é relativamente alto, assim como os riscos da atividade. A expansão pode ser realizada com capital próprio ou com a participação de investidores institucionais. Tanto na TAM como na GOL, ocorreu a participação destes investidores, bem como a abertura do capital com objetivo de aumentar a capitalização e diluir o risco. Não foi identificado investimento direto de fundos de pensão nestas duas empresas aéreas brasileiras. Apenas durante um curto período de tempo na VARIG, quando, no leilão, ela foi arrematada por um gestor de investimentos, cujos recursos eram majoritariamente de fundos de pensão norte-americanos. Também não foram identificados recursos diretos da BNDESPar (BNDES Participações, subsidiária dos BNDES que atua na indústria de capital de risco) em nenhuma empresa aérea. Para o setor aéreo, o BNDES opera uma linha específica para a aquisição de aeronaves nacionais, notadamente aquelas produzidas pela EMBRAER. Tanto a AZUL Linhas Aéreas como a WEBJET estariam se beneficiando desta linha de financiamento (BALARIN, 2009).

O caso da criação da empresa GOL ilustra como membros da família Constantino teriam mudado sua cultura de negócios. Durante a experiência de constituição da empresa, teriam ocorrido mudanças nas estruturas cognitivas de representantes da família controladora da empresa GOL e um novo repertório de conhecimentos, típico daqueles que operam na indústria de capital de risco, teria sido assimilado. $\mathrm{O}$ grupo passou, então, a operar como investidor de private equity. 
Além da semelhança entre as estratégias financeiras das duas principais empresas estudadas, foi possível constatar que, apesar de a empresa TAM deter a maior fatia de mercado (market share) - o que, segundo a análise econômica tradicional, faz dela a líder do setor -, no campo financeiro, a empresa GOL definiu a agenda de prioridades estratégicas. $\mathrm{O}$ modelo "baixo custo, baixa tarifa" (low cost, low fare) foi introduzido no mercado brasileiro de transporte aéreo em sincronia com a preparação para a abertura do capital da empresa e seu ingresso no mercado de ações, enfatizando o compromisso com as "boas práticas de governança corporativa". Entre as inovações estratégicas, destaca-se a adoção de incentivos aos seus profissionais, que tiveram participação mais direta na estruturação inicial da empresa, por meio das "opções de ações" (stock options).

Contudo, a crise aérea, seguida da crise financeira internacional, fez com que as ações da empresa GOL desvalorizassem mais do que as da TAM. Os motivos seriam múltiplos, mas destacaram-se a aquisição da VARIG (dispêndio financeiro, questionamento quanto à imagem de empresa enxuta, herança de rotas menos lucrativas, etc.) e a forte interferência da família na gestão da empresa, abalando a imagem da GC apresentada. Notem-se as divergências entre o pai e os filhos em relação a manter ou não aberto o capital da empresa, ou ainda, o envolvimento de Constantino Oliveira, conhecido como "Sr. Nenê", em escândalos imobiliários, que teria levado à renúncia de Joaquim Roriz (GANTOIS; STUDART, 2007).

Se durante as décadas de 1980 e 1990, as organizações industriais buscavam legitimidade por meio da adoção dos pacotes gerenciais ligados ao "modelo japonês", conforme indicado por Zilbovivius (1999), atualmente, as "boas práticas de governança corporativa" seriam a nova roupagem que garantiria legitimidade às empresas que atuam nos seus espaços industriais e em mercados de capitais. Segundo Fligstein (2001), a concepção de controle da empresa de acionistas teria se contraposto ao excesso de poder nas mãos dos gerentes, levando à redução do quadro de pessoal e à mudança na gestão, por meio da reengenharia. Mas, se por um lado a versão atualizada enxuga os níveis intermediários de gerência, por outro, ela aumenta o poder e o prestígio dos altos executivos, conforme indicado pela GC das empresas, tanto em relação aos conselheiros como aos presidentes executivos (CEOs) e vice-presidentes financeiros (CFOs).

A comparação entre os perfis dos conselheiros e diretores das duas empresas permite identificar a preocupação destas em compor seus quadros executivos com profissionais com experiências complementares nas áreas operacional, financeira e política. Em ambas, no Conselho de Administração, ocorre a participação significativa de membros das famílias controladoras, além de profissionais detentores de determinados tipos de capitais, no sentido de Bourdieu, que seriam fundamentais na elaboração e na execução das estratégias do negócio. O capital político, por exemplo, na TAM, foi representado até abril de 2007 por Henri Philippe Reichstul (ex-presidente da Petrobrás; ex-conselheiro do BNDES e da Caixa Econômica Federal, tendo sido ex-presidente do grupo BRENCO), sucedido por Pedro Pullen Parente (ex-ministro chefe da Casa Civil; ex-secretário executivo da Fazenda, atual CEO da BÜNGE no Brasil). Na empresa GOL, Antonio Kandir (ex-deputado; ex-ministro; ex-conselheiro da DATASUL; conselheiro da MEDIAL SAUDE e PROVIDÊNCIA S.A.) tem ocupado a posição de conselheiro independente e articulador político do grupo. Mas, provavelmente, a principal contribuição de Kandir tenha sido apresentar os caminhos para que a família Constantino adquirisse a cultura de private equity.

Froud e Williams (2007) indicam que, nos últimos anos, os fundos de private equities têm ampliado suas participações nos mercados financeiros internacionais. A presença dos gestores de private equities nos negócios da indústria do transporte aéreo comercial brasileiro confirma a hipótese do domínio da lógica financeira nesse campo organizacional e ilustra o papel central desses atores no processo de difusão da lógica financeira nos espaços industriais brasileiros. O conjunto dos dados empíricos apresentados indica como, no plano estratégico das duas empresas que dominam o mercado de transporte aéreo brasileiro, a dimensão financeira tem prevalecido, seja pela participação de recursos de private equity, seja pela valorização dos profissionais com ampla experiência em mercados financeiros, ou ainda pela adoção da Governança Corporativa como forma atualizada de gestão empresarial.

\section{Agradecimentos}

Engenharia de Produção, Departamento de Engenharia de Produção, Universidade Federal de São Carlos - UFSCar, Núcleo de Estudos em Sociologia Econômica e das Finanças da UFSCar - NESEFI.

\section{Referências}

ADACHI, V.; MANDL, C.; CAMPASSI, R., Copiar o modelo da Gol pode não ter sido a melhor idéia para a TAM. Valor Econômico, São Paulo, 27 dez. 2006.

ADACHI,V. Fundos preparam saída do capital da TAM. Valor Econômico, São Paulo, 17 out 2005.

BALARIN, R. Governo financia 1/3 dos jatos da Embraer. Valor Econômico, São Paulo, 23 jul. 2009.

BOLTANSKI, L.; CHIAPELLO, E. O novo espírito do capitalismo. São Paulo: Martins Fontes, 2009.

BOURDIEU, P. O Campo Econômico. Política \& Sociedade, n. 6, p. 15-57, 2005. 
BOURDIEU, P. O Poder simbólico. Rio de Janeiro: Bertrand Brasil, 1989.

CAMPASSI, R. Depois da crise, TAM afasta executivo de planejamento. Valor Econômico, São Paulo, 01 mar. 2007.

CAMPASSI, R. Executivo da Gol troca companhia pela rival TAM. Valor Econômico, São Paulo, 04 set. 2007.

CAMPASSI, R. Pequot Capital vai investir em nova aérea no Brasil. Valor Econômico, São Paulo, 09 abr. 2008.

CAMPASSI, R.; ADACHI, V. TAM encara sua crise de identidade. Valor Econômico, São Paulo, 03 maio. 2007.

DEZALAY, Y.; GARTH, B. A Dolarização do Conhecimento Técnico Profissional e do Estado: processos transnacionais e questão de legitimação na transformação do Estado, 1960-2000. Revista Brasileira de Ciências Sociais, v. 15, n. 43, p. 163-176, 2000.

DIMAGGIO, P. J. Aspectos culturais da ação e da organizaçõ econômica. In: MARQUES, R.; PEIXOTO, J. (Org.). A Nova Sociologia Econômica. Oeiras: Celta Editora, 2003.

FAMA, E. F. Agency Problems and Theory of Firm. Journal of Political Economy, v. 88, n. 2, p. 288-307, 1980. http://dx.doi.org/10.1086/260866

FLIGSTEIN, N. O mercado enquanto política: Uma abordagem político-cultural às instituições de mercado. In: MARQUES, R.; PEIXOTO, J. (Org.). A Nova Sociologia Econômica. Oeiras: Celta Editora, 2003.

FLIGSTEIN, N. The Architecture of Markets: An Economic Sociology of Twenty-first-century. Princeton: Princeton University Press, 2001.

FLIGSTEIN, N. The transformation of corporate control. Cambridge: Harvard University Press, 1990.

FOLKMAN, N. et al. Working for themselves?: Capital market intermediaries and present day capitalism. CRESC, The University of Manchester, 2006. Disponível em: <http://www.cresc.ac.uk/publications/documents/ wp25.pdf $>$.

FROUD, J.; WILLIAMS, K. Private equity and the culture of value extraction. Version 2. CRESC, The University of Manchester, 2007. Disponível em: <http:// www.cresc.ac.uk/publications/documents/wp31.pdf $>$.

GANTOIS, G.; STUDART, H. As polêmicas de seu nenê. Revista Istoé Dinheiro, 11 jul. 2007. Disponível em: <http://www.istoedinheiro.com.br/ noticias/3067_AS+POLEMICAS+DE+SEU+NENE $>$.

GRÜN, R. Atores e Ações na Construção da Governança Corporativa Brasileira. Revista Brasileira de Ciências Sociais, v.18, n. 52, p. 121-143, 2003.

GRÜN, R. A Evolução Recente do Espaço Financeiro no Brasil e Alguns Reflexos na Cena Política. Dados, v. 47, n. 1, p. 5-47, 2004.

GRÜN, R. Convergência das Elites e Inovações Financeiras: a governança corporativa no Brasil. Revista Brasileira de Ciências Sociais, v. 20, n. 58, p. 67-90, 2005.

GRÜN, R. Difusão dos fundos de private equities (PES) e transformações do capitalismo no Brasil recente. In: MONDADORE, A. P. C. et al (Orgs.). Sociologia econômica e das finanças: um projeto em construção. São Carlos: EdUFSCar, 2009.

HIRSH, P. M.; DE SOUCEY, M. Organizational Restructuring and Its Consequences: Rhetorical and Structural. Annual Review of Sociology, p.171-189, 2006. http://dx.doi.org/10.1146/annurev. soc.32.061604.123146

INSTITUTO BRASILEIRO DE GOVERNANÇA CORPORATIVA - IBGE. Disponível em: <www. ibgc.org.br>. Acesso em: 22 maio 2009.

JARDIM, M. A. C. Entre a solidariedade e o risco: sindicatos e fundos de pensão em tempos de governo Lula. 2007. 421f. Tese (Doutorado)-Universidade Federal de São Carlos, São Carlos, 2007.

KOMATSU, A. Dono da Webjet aguarda lei para vender fatia de até 49\%. Valor Econômico, São Paulo, 17 mar. 2010.

LOVADINE, D. Análise Econométrica Estrutural da Conduta Competitiva: Estudo de Caso do Transporte Aéreo Pós-Liberalização. Revista de Literatura dos Transportes, v. 3, n. 1, 2009.

MONTEIRO, C. F. Estado e mercado no transporte aéreo brasileiro pós-reformas. Política \& Sociedade, v. 8, n. $15,2009$.

MUNDO NETO, M. Desenvolvimento do mercado do etanol: aproximação da indústria sucroalcooleira e da indústria de capital de risco no Brasil. In: ENCONTRO ANUAL DA ANPOCS, 32., 2008, Caxambu. Anais... NEAD, 2008.

PALHARES, G. L. Transportes Turísticos. São Paulo: Aleph, 2002. (Série Turismo).

PROVIDÊNCIA. Governança Corporativa. Disponível em: <http://www.providencia.riweb.com.br/>. Acesso em: 03 jun. 2010.

RITTNER, D. Estrangeiros compram parte da BRA por R\$ 180 milhões. Valor Econômico, São Paulo, 20 dez. 2006.

SILVA JÚNIOR, A. Vendas de ações rendem US\$ 4 bi. Valor Econômico, São Paulo, 25 abr. 2006

TAM LINHAS AÉREAS S/A. Disponível em: <http:// www.tam.com.br>. Acesso em 21/05/2008.

VALOR ONLINE. BRA cogita abrir capital para financiar compra de aviões. São Paulo, 21 ago. 2007a.

VALOR ONLINE. BRA sai de cena e crise do setor aéreo continua. São Paulo, 12 nov. 2007b.

VALOR ONLINE. TAM promove mudanças no conselho de administração. São Paulo, 27 abr. 2007c.

VALOR ONLINE. Dono da JetBlue lança companhia aérea no Brasil com investimento recorde de US\$ 150 milhões. São Paulo, 27 mar. 2008.

ZILBOVIVIUS, M. Modelos para a Produção, Produção de Modelos: Gênese, Lógica e Difusão do Modelo Japonês de Organização da Produção. São Paulo: FAPESP/Annablume, 1999.

ZILBOVIVIUS, M.; DIAS, A. V. C. Working for value creation: some issues on financialisation and new forms of work organization. In: GERPISA INTERNATIONAL COLlOQUIUM, 13., 2005, Paris. Proceedings... Paris, 2005. p.16-17. 